\title{
ESTRATÉGIAS PARA INCLUSÃO DE BLOGS NA NOVA ORDEM DE COMUNICAÇÃO DIGITAL
}

\author{
Strategies to include blogs in new digital communication order \\ Estrategias para la inclusión de los blogs en el nuevo orden de la comunicación \\ digital
}

Lutiana Casaroli

Doutoranda em Linguística pelo Programa de Pós-Graduação em Letras e Linguística, da Faculdade de Letras, da Universidade Federal de Goiás (UFG) lutiana.rp@gmail.com

\begin{abstract}
Juliane Barcelos de Oliveira Especialista em Gestão e Avaliação da Informação da Faculdade de Informação e Comunicação, da Universidade Federal de Goiás (UFG) Juliane.barcelos@gmail.com
\end{abstract}

\section{Resumo}

É objetivo desse texto levantar conceitos essenciais para a comunicação digital dentro da cultura dos blogs e das mídias sociais digitais, evidenciando seus papéis como espaços de sociabilidade, colaboração, interação e compartilhamento, além de propor algumas estratégias para tentar manter a relevância dos blogs nesse novo cenário, através de uma pesquisa qualitativa, descritiva e teórica acerca da literatura existente sobre o assunto. Foram criadas quatro categorias metodológicas, avaliando as mídias sociais digitais escolhidas e as formas como, dadas suas características específicas, auxiliam na manutenção dos blogs como uma mídia social digital relevante no cenário da comunicação digital atual. Concluiu-se que as mídias sociais digitais podem funcionar como braços midiáticos e garantir a interação e, consequentemente, a sobrevivência dos blogs na nova ordem da comunicação digital

Palavras-chave: Blogs. Mídias sociais digitais. Comunicação digital.

\begin{abstract}
It's the objective of this paper to evince essential concepts for digital communication within the culture of blogging and online social media, showing their roles as areas of sociability, collaboration, interaction and sharing, and also to propose some strategies to try to maintain the blogging relevance in this new scenario, through a qualitative, descriptive and theoretical research on the existing literature on the subject. Four methodological categories were created, evaluating the chosen digital social media and the ways in which, given their specific characteristics, they help to maintain blogs as a relevant digital social media in today's digital communication scenario. It was concluded that online social media can function as media arms and ensure interaction, and consequently the survival of blogs on the new order of digital communication.
\end{abstract}


Key words: Blogs. Online social media. Digital Communication.

\section{Resumen}

Es el objetivo de este texto nominar conceptos esenciales para la comunicación digital dentro de la cultura de los blogs y de las redes sociales digitales, destacando sus funciones como áreas de sociabilidad, colaboración, interacción y compartición, y proponer algunas estrategias para tratar de mantener la importancia de los blogs en este nuevo escenario, a través de una encuesta cualitativa, descriptiva y teórica acerca de la investigación sobre el tema. Cuatro categorías metodológicas fueron escogidas, evaluando los medios sociales digitales elegidos y las formas en que, dadas sus características específicas, ayudan a mantener los blogs como medios sociales digitales pertinentes en el escenario actual de la comunicación digital. Se concluyó que los medios sociales digitales pueden funcionar como brazos mediáticos y asegurar la interacción, en consecuencia, asegurando la supervivencia de los blogs en el nuevo orden de la comunicación digital.

Palabras clave: Blogs. Redes sociales digitales. Comunicación digital.

\section{INTRODUÇÃO}

Vive-se em uma sociedade altamente integradora: a informação e a produção desta não são mais atributos unilaterais, tão pouco estáticos ou fixos. As distâncias físicas não são mais limitadoras para conexões interpessoais e isso é perceptível na forma como as comunicações têm sido estabelecidas: grande parte das informações transmitidas e recebidas são descentralizadas, dinâmicas e voláteis, tanto quanto esta transmissão.

Como consequência da facilidade de obtenção e divulgação dessa informação, de uma cultura que estimula a participação e do estreitamento das relações pessoais torna-se cada vez mais simples e fácil manter e perpetuar esta estrutura comunicacional. Mais se interage, participa, cria e renova conceitos e paradigmas. Nunca tanto conteúdo foi e é produzido simultaneamente e ele está cada vez mais pluralizado e eclético.

Tais propriedades começaram a ser mais estudadas por O'Reilly (2009, p.4), quando foi criado o conceito de Web 2.0, também chamada de web colaborativa ou ainda de Web Social. Em relação à Web 1.0 não houve mudanças significativas no âmbito tecnológico, porém os conteúdos digitais se tornaram mais dinâmicos e colaborativos $\mathrm{Na}$ Web 2.0 é permitido às pessoas uma participação multilateral, estendendo as oportunidades de criação de novos conteúdos e conhecimentos, gerados a partir dessas relações em rede.

No escopo da comunicação, na Web 2.0, a interação entre as pessoas se dá pela não existência de uma hierarquização do fluxo comunicacional, segundo O'Reilly (2007, p.9). Para Silva (2007, p.8), a rede passa a ser vista como uma plataforma, tirando do usuário a 
condição de somente observador e lhe concedendo a oportunidade de ser também o criador desse conteúdo. Ferramentas como mídias sociais digitais, blogs, wikis, e outros compartilhadores de arquivos são os principais responsáveis por essa dinamicidade de criação, sendo a fundação desse ambiente de troca e criatividade através de participações colaborativas, segundo Wheeler $(2007$, p. 3$)$.

Dentre estas ferramentas citadas, faremos dos blogs nosso objeto de estudo enquanto meio de colaboração, interação, compartilhamento e sociabilidade. Diante do exposto, vamos definir e conceituar a ferramenta blog, além de sua posição e relevância na criação de conteúdo digital no ciberespaço. Abrangeremos como ele mudou e vem mudando a forma de produção de conteúdo virtual ao longo dos anos.

Exibiremos ainda uma variedade de novas mídias sociais digitais e como elas têm disputado seus lugares em meio à web no viés da comunicação digital. Veremos ainda conceitos como sociabilidade, interação, colaboração e compartilhamento, o comportamento das mídias sociais digitais no âmbito digital e como elas se relacionam e representam a interação do ciberespaço.

Em posse do referencial teórico levantado, foi possível criar quatro diferentes categorias metodológicas, nas quais avaliamos e dividimos as funcionalidades das mídias sociais digitais escolhidas e indicamos, posteriormente, como tais funcionalidades podem ajudar a manter a relevância dos blogs no cenário de comunicação digital atual. Evidenciamos assim, também, a internet como ferramenta potencializadora do empoderamento do leitor por meio da informação e o papel que os blogs desempenham nesse processo.

\section{CIBERESPAÇO E A INTELIGÊNCIA COLETIVA}

Para Levy (2007, p. 104), o ciberespaço pode ser entendido como uma nova forma de comunicação surgida da interligação mundial dos computadores. $O$ termo especifica não apenas a infraestrutura mundial da comunicação digital, mas também as informações que ela detém, além pessoas que navegam e fomentam esse universo. O ciberespaço representa um estágio avançado de auto-organização social, ainda que em desenvolvimento: a inteligência coletiva.

A inteligência coletiva, ainda para Levy (2007, p. 31), “é uma inteligência distribuída por toda parte, incessantemente valorizada, coordenada em tempo real, que resulta em uma mobilização efetiva das competências". Ele defende que cada pessoa tem a sua própria 
inteligência resultante de suas experiências pessoais e que ela serve como um modo de interação social uma vez que possibilita interação com outras pessoas.

O ciberespaço pode ser entendido, então, como o local onde a inteligência coletiva é formada a partir da interação entre as pessoas que, como organismos individuais que são, alavancam a troca de informações por meio de comunidades virtuais, ou ciberculturas, cujo objetivo maior está em promover amplas conexões entre seus participantes. E é esse espaço onde a interação acontece, que promove mudanças na forma como cada indivíduo passa a assimilar aquela informação consequente das interações. Para Lemos (1996, p. 2), o ciberespaço não é uma entidade puramente virtual e não está desligado da realidade: é um espaço intermediário. E nele todos são agentes de interação. Conceitos como interação ficarão mais claros nas sessões seguintes.

\section{BLOG E A DESCENTRALIZAÇÃO DA INFORMAÇÃO}

O termo "weblog" foi criado por Jorn Barger em 1997. A união das palavras "web" como rede e "log" como um registro de eventos, a palavra weblog, significa, de forma simplificada, um diário virtual. Com o passar do tempo, o weblog, tornou-se somente blog.

Para Gomes (2005, p. 200) por outro ângulo,

(...) é uma página na Web que se pressupõe ser atualizada com grande frequência através da colocação de mensagens - que se designam "posts" constituídas por imagens e/ou textos normalmente de pequenas dimensões (muitas vezes incluindo links para sites de interesse e/ou comentários e pensamentos pessoais do autor) e apresentadas de forma cronológica, sendo as mensagens mais recentes normalmente apresentadas em primeiro lugar.

O conteúdo dos blogs é produzido por um ou mais autores (colaboradores) e também pelos leitores que participam comentando no próprio post ou em alguma outra mídia em que a matéria tenha sido divulgada. Estruturalmente, um blog se apresenta como um diário ou registro, organizado em ordem histórica decrescente. Em relação à temática, a pluralidade de tipos de blogs é vasta e as entradas ou posts são compostas ainda por imagens, vídeos, links e áudios.

Segundo, Marlow (2004, p. 3), por outro lado, os blogs são considerados mídias, que diferentemente das demais possuem caráter social, expresso através da sua função conversacional, levando em conta os textos publicados, as ferramentas anexadas, como os 
comentários. Para ele "Weblogs constituem uma conversação massivamente descentralizada onde milhões de autores escrevem para a sua própria audiência".

Outros autores ainda, veem os blogs como artefatos culturais, como Shah (2005, p. 8):

Um artefato cultural, para evitar qualquer confusão, pode ser claramente definido como um repositório vivo de significados compartilhados produzido por uma comunidade de idéias. Um artefato cultural é um símbolo de comunhão (no sentido não violento, não religioso da palavra). Um artefato cultural se torna infinitamente mutável e gera muitas autorreferências e narrativas mutuamente definidoras mais do que cria uma narrativa mestra linear. (...) [sua legitimação se dá] pelas práticas vividas das pessoas que os criaram.

De acordo com Primo (2003, p. 3-12) a categorização dos blogs é feita de acordo com a quantidade de autores que nele escrevem: sendo eles dos tipos individuais ou colaborativos. O blog individual pode ser subdivido em pessoal ou profissional. Este primeiro é composto de produções individuais e não está ligado a nenhum grupo de pessoas ou instituição. Já no blog profissional, o autor é especialista em um assunto, sendo ele de qualquer área do conhecimento. Dentre os blogs colaborativos estão os coletivos, composto de mais um autor, geralmente entusiastas sobre um mesmo assunto especifico. Outro tipo de blog coletivo é o organizacional, onde o conteúdo está ligado de forma direta a uma determinada instituição.

\section{AS MÍDIAS SOCIAIS DIGITAIS E SEUS DIFERENCIAIS}

O blog não é a única mídia social digital que proporciona interação entre seus usuários e está longe de ser a maior, porém, talvez seja uma das mais antigas que perdura até hoje e isso evidencia sua consolidação. Entretanto, outras mídias têm ocupado uma porcentagem expressiva de utilização entre as pessoas, por inúmeros fatores. A seguir, conceituaremos mídias sociais digitais, levantaremos alguns exemplos das mais utilizadas atualmente e seus diferenciais.

As mídias sociais têm sido ferramentas valiosas para possibilitar a troca de informação e o compartilhamento de conteúdo aos usuários da web 2.0. As mídias sociais podem ser sites e/ou aplicativos disponíveis para qualquer pessoa produzir e distribuir conteúdo, que tenha acesso a internet. Para Saad (2011, p. 4), as mídias sociais representam um fenômeno exclusivo da web 2.0, enquanto para Recuero $(2008$, p. 3) a web 2.0 não inaugura a mídia social, mas a intensifica. 
Então, o que difere as mídias sociais digitais não é a capacidade comunicativa, já existente em outros meios de comunicação de massa, e sim as possibilidades de interação mútua, segundo Primo (2007, p. 3), no espaço da própria mídia, permitindo a sociabilidade entre os interagentes.

Mayfield (2008, p. 5) afirma que as principais características que tornam um site uma ferramenta de mídia social seriam a participação, por meio da qual é atenuada a linha entre mídia e público; a abertura a comentários e compartilhamento de informações; a conversação que se contrapõe ao formato de transmissão da mídia broadcast (de transmissão); a criação de comunidade e sua visibilidade; e a conectividade por meio de links a outros sites, recursos e pessoas.

Junior (2009, p.3) considera que a principal marca da mídia social é a participação ativa dos usuários em um processo de "integração de informações", que constitui o que poderia ser classificado como uma "esfera pública interconectada". Ele destaca as possibilidades de “(...) criação, compartilhamento, comentário, avaliação, classificação, recomendação e disseminação de conteúdos digitais de relevância social de forma descentralizada, colaborativa e autônoma tecnologicamente".

Assim, podemos afirmar que uma ferramenta de mídia social pode servir de suporte às redes sociais dos atores, como um verdadeiro braço midiático, auxiliando a sobrevivência dos blogs nessa nova ordem da comunicação digital. Entendemos que ela só será mídia em função da potencialidade de apropriação coletiva do conteúdo, em um modelo descentralizado que se opõe à lógica centralizadora de transmissão da mídia de massa.

\subsection{Snapchat}

O Snapchat ${ }^{2}$ é um aplicativo de mensagens com base de imagens e/ou vídeos. O aplicativo é dividido em três telas (snap, chat e histórias) que acabam formando o próprio nome do app e, segundo os criadores, são resultado da evolução da forma como as pessoas utilizam fotos. O Snapchat sempre começa com um 'snap', para começar uma conversa, o usuário sempre tem que tirar uma foto. Por isso o aplicativo começa pela câmera. À esquerda da câmera, há uma lista com todas as conversas do usuário com as pessoas as quais os usuários recebem e enviam fotos.

2 https://www.snapchat.com/ 
Ao tirar um 'snap', o usuário pode escolher entre enviar para amigos ou adicioná-lo a uma história, um arquivo temporário que mantém todos os 'snaps' do dia em ordem cronológica. $\mathrm{O}$ usuário pode ainda escolher quanto tempo de visualização terá a foto ou vídeo que ele enviar. Esse é o diferencial da mídia Snapchat em relação à todas as outras baseadas em linhas do tempo: as outras mídias sociais digitais apresentam suas publicações em ordem inversa, então o usuário vê o fim antes de ver o começo.

Figura 1: interface das três telas do aplicativo Snapchat

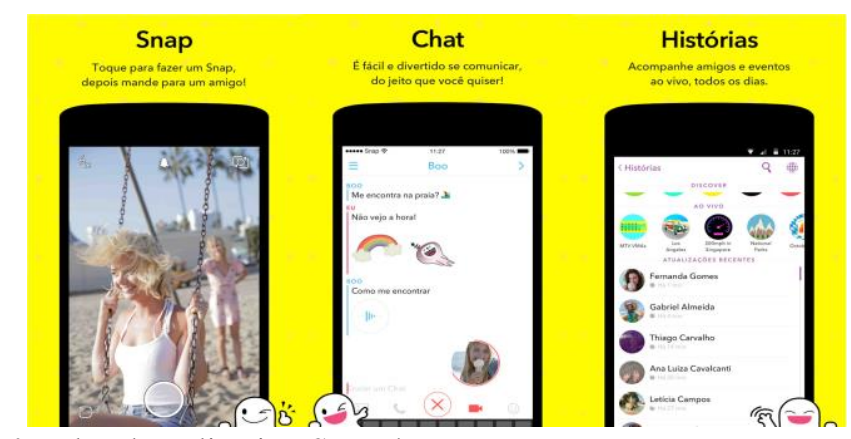

\subsection{Youtube}

O YouTube ${ }^{3}$ é um site de compartilhamento de vídeos enviados pelos usuários através da internet. O YouTube oferece um fórum para as pessoas se conectarem, se informarem e inspirarem umas às outras por todo o mundo, bem como atua como plataforma de distribuição para criadores de conteúdo original e anunciantes grandes e pequenos.

Qualquer usuário com uma conta cadastrada pode enviar um vídeo, comentar ou curtir os vídeos de outros usuários. Ainda é possível enviar vídeos como respostas à outros vídeos. O Youtube, diferentemente do Snapchat é uma mídia social digital multi-plataforma: pode ser acessada em diferentes dispositivos como desktop (site), tablet e celular (aplicativo). Para efeito de concisão, vamos ilustrar somente a plataforma mobile da mídia.

A tela inicial do aplicativo do Youtube mostra os vídeos recomendado para o usuário baseado nas preferências de canais, vídeos e temáticas dele. Na tela seguinte, de inscrições, são exibidos, em ordem decrescente, os vídeos submetidos pelos administradores dos canais nos quais o usuário está inscrito. Na tela de conta, são exibidas informações a respeito do dono da conta, como histórico (lista com os vídeos assistidos), notificações, entre outros.

3 https://www.youtube.com/?gl=BR\&hl=pt 


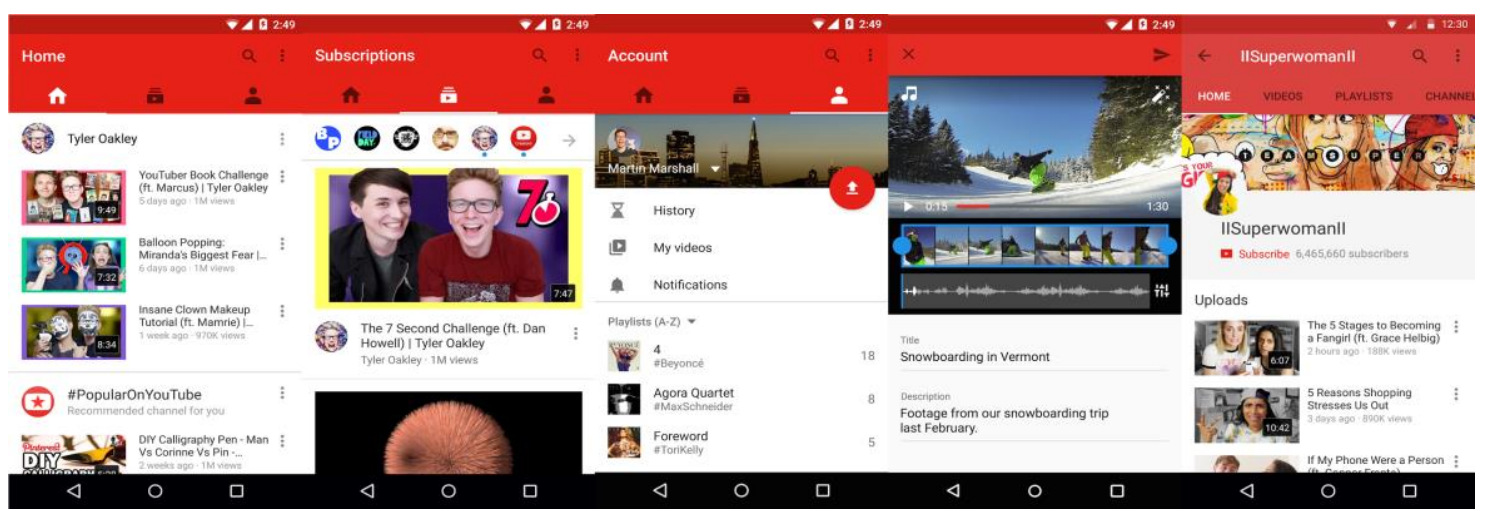

Figura 2. Interface das principais telas do aplicativo do Youtube

A quarta tela da Figura 2 mostra a interface de envio de um vídeo pelo usuário, onde ele pode definir também um título e uma descrição para seu vídeo. Por último, na quinta tela da Figura 2 temos a aparência de um canal, onde o usuário pode navegar entre os vídeos enviados pelo dono do canal, as playlists compostas por vídeos com assuntos ou temas relacionados, visualizar o número de inscritos do canal, entre outros.

\subsection{Instagram}

No Instagram ${ }^{4}$ o usuário escolhe uma imagem armazenada na memória ou tira uma foto na hora para compartilhar com os seus seguidores - podem compor uma conta pública ou privada e a pública. Há ainda a possibilidade de compartilhar essas imagens postadas em outras mídias sociais digitais, como o Twitter. No Instagram, os usuários podem curtir e comentar as fotos uns dos outros e há ainda o uso de hashtags(\#) para que seja possível encontrar imagens relacionadas a um mesmo tema, mesmo que as pessoas que tiraram essas fotos não sejam tenham se adicionado como amigas.

Na Figura 3 podemos ver a interface do aplicativo e suas principais telas onde: na parte inferior da tela estão os ícones de navegação entre as telas do aplicativo, sendo elas: início, explorar, postar foto, notificações e conta. A primeira tela é a de uma foto postada, vista na tela de início, onde o usuário tem a opção de curtir (ao clicar no ícone de coração) e/ou comentar (ao clicar no ícone do balão de fala). A segunda tela é referente a tela explorar onde o aplicativo mostra imagens relacionadas ao que o usuário segue ou costuma curtir e

4 https://www.instagram.com/ 
comentar. Ainda na tela de explorar, na parte superior temos um campo para pesquisar pessoas, marcações (hashtags) ou lugares.

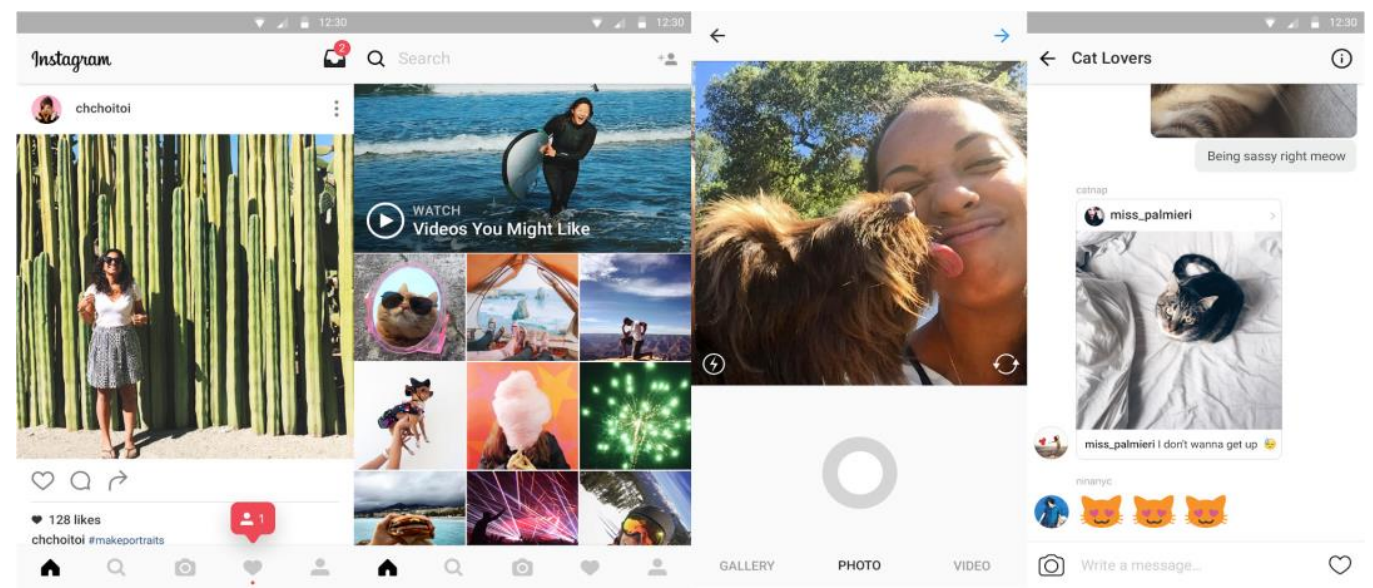

Figura 3. Interface das principais telas do aplicativo do Instagram

A terceira tela da Figura 3 é a de postar foto, onde o usuário, após decidida a foto que irá postar pode adicionar ou não filtros na imagem, além de uma descrição, marcar amigos e locais. A última tela da Figura 3 mostra o 'Direct message' (mensagem direta) onde os usuários podem trocar mensagem, imagens e links entre si.

\subsection{Twitter}

Twitter ${ }^{5}$ é uma mídia social digital no formato de micro-blog, que permite aos usuários enviar e receber atualizações pessoais de outros contatos, em textos de até 140 caracteres. Os textos são conhecidos como tweets, e podem ser enviados por meio do site do serviço, por SMS, ou por aplicativos em dispositivos mobile.

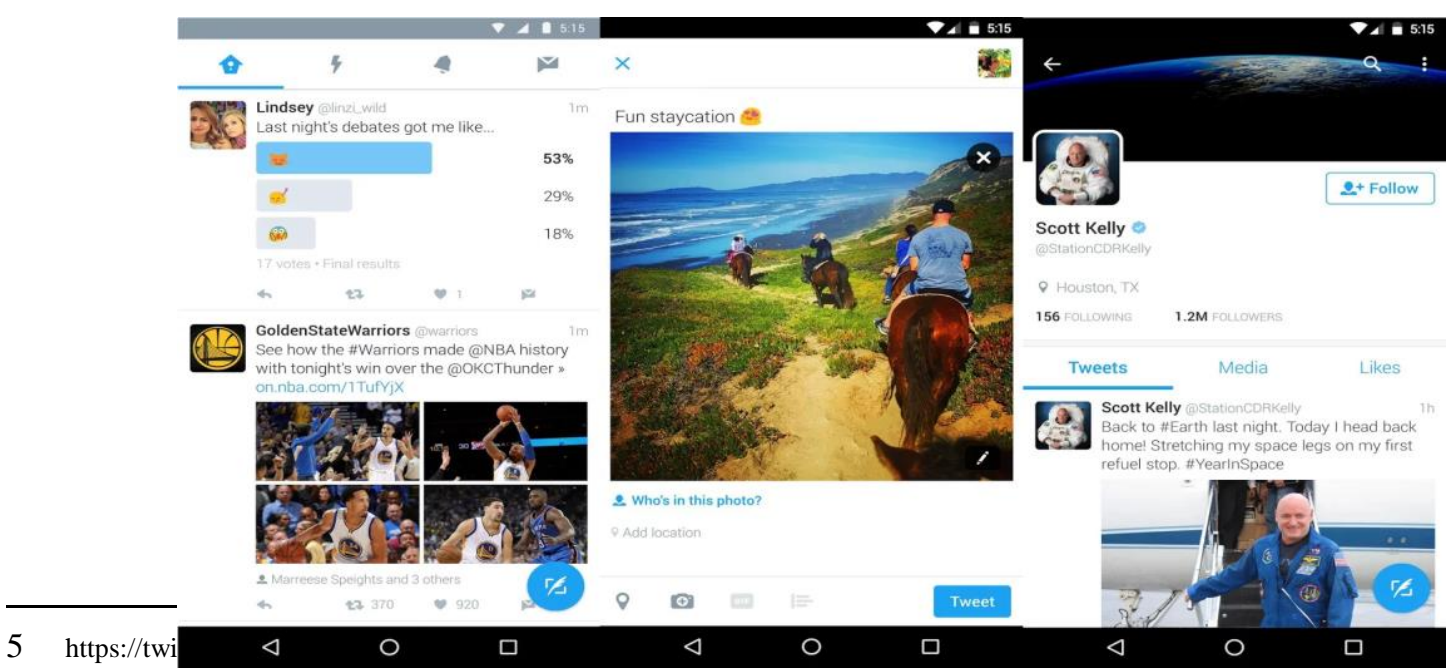


Figura 4. Interface das principais telas do aplicativo do Twitter

As atualizações são exibidas no perfil de um usuário em tempo real e também enviadas a outros usuários seguidores que estejam seguindo a pessoa de seu interesse para recebê-las. Além das micro-mensagens, o Twitter atualmente disponibiliza a opção de também compartilhar imagens e vídeos, através de encurtadores de URL's. O Twitter possui ainda a opção de retweet ou RT, que consiste em replicar uma determinada mensagem de um usuário para a lista de seguidores, dando crédito ao seu autor original.

Os trending topics ou TTs, que são uma lista em tempo real das palavras mais postadas no Twitter, seja em determinada região ou por todo o mundo, determinado nas configurações pelo dono da conta, também é outro mecanismo que serve de "termômetro" sobre quais são os assuntos mais discutidos pelas pessoas na internet naquele momento.

$\mathrm{Na}$ Figura 4 podemos ver as principais telas da interface do aplicativo do Twitter. $\mathrm{Na}$ primeira tela temos a linha do tempo do usuário da conta, onde são exibidos, em ordem decrescente de tempo, as postagens das pessoas que ele segue. $\mathrm{Na}$ segunda tela temos a interface da tela de postagem onde o usuário pode compartilhar com seus seguidores mensagens (respeitando o limite de caracteres), imagens ou links. Na última tela da Figura 4 está ilustrada o perfil do usuário dono da conta, onde podem ser observados todos os seus tweets (mensagens), informações sobre o mesmo e um botão com a opção de começar a seguir o usuário.

\section{METODOLOGIA}

Tendo como base o referencial teórico e a recorrência de conceitos e denominações foi possível distinguir alguns verbetes que se ressaltaram nas pesquisas sobre comunicação digital. A partir destes, foram criadas quatro categorias metodológicas que consideramos essenciais para tentar integrar o blog na nova ordem de comunicação digital e garantir que ele não desapareça neste novo cenário. As categorias são: colaboração, interação, compartilhamento e sociabilidade. Vamos apresentar seus significados a seguir e então indicar como cada uma das mídias sociais digitais escolhidas se comporta para cada uma das categorias. Feito isso, vamos apontar como cada mídia social digital pode auxiliar os blogs em cada uma destas quatro categorias. 
Para o significado dos verbetes foi pesquisado o dicionário Michaelis ${ }^{6}$ e seus resultados foram transcritos abaixo.

Por colaboração, entende-se como a ação de colaborar ou ajudar, feita esta pelos colaboradores, aqueles que colaboram ou ajudam outro em suas funções. Apreende-se ainda como colaboração uma reunião de pelo menos duas pessoas trabalhando juntas para produzir ou utilizar algo. Segundo o dicionário Michaelis, tem-se que:

\section{colaboração}

co.la.bo.ra.ção

$\boldsymbol{s} \boldsymbol{f}$ (colaborar+ção) 1 Ato de colaborar; cooperação; ajuda. 2 Trabalho feito pelos colaboradores. 3 Conjunto dos colaboradores. 4 Inform Reunião de duas ou mais pessoas que trabalham juntas para produzir ou utilizar uma aplicação multimídia.

Vale ressaltar ainda o conceito que o dicionário apresenta para colaborador:

\section{colaborador}

co.la.bo.ra.dor

adj (colaborar+dor2) Que colabora. sm 1 Aquele que colabora ou ajuda outro em suas funções; cooperador. 2 Pessoa que, sem pertencer ao quadro de funcionários de uma empresa, trabalha para ela habitualmente ou alguma vez.

Em seguida, quando analisamos o conceito de interação, temos uma ação recíproca de pelo menos dois agentes entre si, ou entre um agente e um equipamento ou ainda, ações e relações entre integrantes de uma sociedade ou entre sociedades de uma comunidade maior.

\section{interação}

in.te.ra.ção

$\boldsymbol{s} \boldsymbol{f}$ (inter+ação) 1 Ação recíproca de dois ou mais corpos uns nos outros. 2 Atualização da influência recíproca de organismos inter-relacionados. $\mathbf{3}$ Ação recíproca entre o usuário e um equipamento (computador, televisor etc.). I. social, Sociol: ações e relações entre os membros de um grupo ou entre grupos de uma sociedade.

Para reciprocidade temos a seguinte definição:

reciprocidade

re.ci.pro.ci.da.de

sf (lat reciprocitate) 1 Caráter ou qualidade de recíproco; correspondência mútua; mutualidade. 2 Sociol Relação social entre indivíduos, grupos e 
instituições implicando deveres, obrigações, prestação de serviços, de um lado, e direitos, compensações e retribuições de outro, dentro da escala de valores e padrões socialmente aprovados.

Por compartilhamento, entende-se como a ação de compartilhar, participar de algo ou alguma coisa, que pode ser usado ou acessado por vários usuários ou agentes de compartilhamento.

compartilhamento

com.par.ti.lha.men.to

sm (compartilhar+mento2) Ato ou efeito de compartilhar. C. de arquivo, Inform: um arquivo que pode ser usado por dois ou mais usuários ou programas em uma rede, normalmente usando o bloqueio de arquivo. $\boldsymbol{C}$. de dados, Inform: um arquivo ou conjunto de dados que pode ser acessado por vários usuários.

Para sociabilidade, compreende-se a tendência natural de viver em sociedade.

sociabilidade

so.cia.bi.li.da.de

sf (lat sociabile+i+dade) 1 Qualidade de sociável. 2 Tendência natural para não viver isolado, mas sim em sociedade. 3 Apresentação e maneiras de quem vive em sociedade. 4 Urbanidade.

Como este pode ser um conceito complexo, apresentamos ainda outras definições para sociabilidade, extraídas agora da literatura sobre o assunto, diferentemente das outras categorias, que somente tiveram seus significados extraídos do dicionário.

Para Bauman (1997, p. 138), socialização e sociabilidade devem ser compreendidos a partir da interação com a estrutura social, porém se referem a processos distintos. "A socialização (pelo menos na sociedade moderna) visa a criar um ambiente de ação feito de escolhas passíveis de serem 'desempenhadas discursivamente', que se concentra no cálculo racional de ganhos e perdas”.

Já a sociabilidade se caracterizada pela ausência de um referencial preestabelecido e pela impossibilidade de se fazer previsões relacionadas às ações dos indivíduos. "A sociabilidade coloca a unicidade acima da regularidade e o sublime acima do racional, sendo, portanto, em geral avessa às regras, tornando o desempenho das regras problemático e cancelando o sentido instrumental da ação", segundo Bauman (1997, p. 138). 


\section{CATEGORIAS METODOLÓGICAS E AS MÍDIAS SOCIAIS DIGITAIS}

É fato que a quantidade mídias sociais digitais existentes atualmente, além das que tem surgido dia após dia influencia na quantidade de tempo que o usuário se dedica a cada uma delas. Para alguém que não seja um profissional especializado no assunto, torna-se difícil acompanhar seus assuntos e personagens favoritos em todas as mídias sociais digitais. Frente a isso, é correto dizer que os blogs podem e têm perdido alcance no cenário da comunicação digital, em relação às opções mais novas, recentes e práticas.

Para cada categoria metodológica criada foram analisadas as características das mídias sociais digitais escolhidas e como é possível perceber funcionalidades destas mídias em cada categoria, além de criar nossas estratégias para atingir os objetivos propostos.

\subsection{Colaboração}

No Snapchat, os usuários podem ajudar-se uns aos outros trocando imagens, informações e mensagens, tirando assim dúvidas através de vídeos, fotos ou até mesmo mensagens pelo chat. A colaboração entre usuários no Instagram pode se dar de diversas formas, seja ajudando os usuários que postam fotos com idéias, comentários ou críticas pelos comentários na foto.

A colaboração entre usuários no Youtube pode se dar de diversas formas, seja ajudando os criadores de vídeos com idéias, comentários ou críticas pelos comentários. A colaboração se dá ainda por exemplo quando um criador de vídeo fazendo vídeos em conjunto com outros, seja pessoalmente ou intercalando segmentos de vídeos de outras pessoas no próprio vídeo. A colaboração entre usuários no Twitter pode se dar com um usuário ajudando outro através da postagem de uma resposta (reply) com idéias, comentários ou críticas.

\subsection{Interação}

Os usuários do Snapchat podem manter um diálogo, conversa ou troca reciproca de informações ao enviar e responder snaps ou mensagens no chat. Já no Youtube, os usuários podem manter um diálogo, conversa ou troca reciproca de informações ao enviar e responder comentários nos vídeos postados.

No Instagram, os usuários podem manter um diálogo, conversa ou troca reciproca de informações ao enviar e responder comentários nas fotos postadas. Ao marcar os outros 
usuários pelo nome, o Instagram garante que, embora os comentários sejam visíveis para todos os usuários, a resposta seja direcionada a um ou mais usuários específicos.

No Twitter. Os usuários podem manter um diálogo, conversa ou troca reciproca de informações ao enviar e responder tweets e replies para os tweets postados por outros usuários.

\subsection{Compartilhamento}

No Snapchat, os usuários podem promover o compartilhamento de imagens, links, mensagens ou vídeos ao enviar snaps no formato de vídeo ou foto uns para os outros. $\mathrm{O}$ compartilhamento pode ser feito ainda pelo chat, trocando-se links e mensagens.

Já no Youtube, os usuários podem promover o compartilhamento de informações através dos comentários nos vídeos ou até mesmo compartilhar links, dos vídeos utilizando outras mídias sociais digitais.

Os usuários do Instagram podem promover o compartilhamento de informações através dos comentários nas fotos ou até mesmo marcando pessoas nas fotos para que o usuário receba uma notificação e veja a foto em que foi marcado.

No Twitter, é possível promover o compartilhamento de informações através dos tweets e respostas (replies) até mesmo marcando pessoas nas respostas para que o usuário receba uma notificação e veja o tweet ou resposta (reply) foto em que foi marcado.

\subsection{Sociabilidade}

A sociabilidade no Snapchat se dá pela interação entre mais de dois usuários. Como o aplicativo não permite que essa interação seja feita simultaneamente, a sociabilidade é alcançada pelo compartilhamento sucessivo entre mais de dois usuários de uma mesma imagem, informação ou link.

A sociabilidade no Youtube se dá pela interação entre mais de dois usuários nos comentários. É possível que mais de um usuário responda um comentário deixado e responda uma resposta de comentário e assim por diante. O Youtube conta ainda com o vídeo resposta, que consiste em enviar um vídeo público como resposta para o vídeo de outra pessoa.

A sociabilidade no Instagram se dá pela interação entre mais de dois usuários nos comentários. É possível que mais de um usuário responda um comentário deixado e responda 
uma resposta de comentário e assim por diante. É possível ainda que um usuário responda a mais de uma pessoa em um comentário.

A sociabilidade no Twitter se dá pela interação entre mais de dois usuários nas respostas (replies). É possível que mais de um usuário responda um tweet deixado e responda uma resposta de tweet (reply) e assim por diante. É possível ainda que um usuário responda a mais de uma pessoa em um tweet ou reply.

Em virtude disso, os blogs podem se tornar cada vez menos nutridos com conteúdos multilaterais e assim, cada vez mais norteados pelas quatro categorias metodológicas criadas: interação, colaboração, compartilhamento e sociabilidade.

\section{APLICAÇÃO DAS CATEGORIAS METODOLÓGICAS}

Vamos levantar agora algumas estratégias, utilizando os recursos e funcionalidades das mídias sociais digitais escolhidas para que os blogs não desapareçam enquanto mídias sociais relevantes. Para ilustrar as categorias foram retirados imagens, trechos e exemplos dos blogs Coisas de Diva ${ }^{7}$, Just Lia $^{8}$ e Blog da Rafaella ${ }^{9}$ e de suas respectivas mídias sociais digitais.

\subsection{Colaboração}

Os administradores ou editores do blog podem trocar informações em formato de vídeo ou mensagem escrita no chat para decidir assuntos pertinentes ao blog. Essa ação pode se aplicar também aos leitores que podem colaborar assim para a criação ou correção de conteúdos no blog pelo Snapchat.

No Youtube, os leitores podem colaborar com a criação ou correção de conteúdos no blog através da caixa de comentários dos vídeos, onde podem solicitar alguma postagem ou assunto a ser discutido na postagem para os administradores do blog.

7 http://www.coisasdediva.com.br/

8 http://www.justlia.com.br/

9 http://www.justlia.com.br/ 


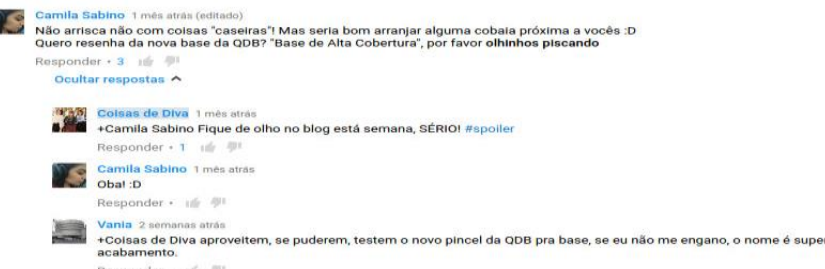

Figura 5. Blogueira divulgando no comentário do Youtube que um conteúdo pedido em comentário por uma leitora será produzido e postado no blog.

A colaboração no Twitter com o intuito de ajudar os blogs se dá ao utilizar a funcionalidade reply para com idéias para postagens, podendo ou não ter imagens ou vídeos anexados a essas respostas.

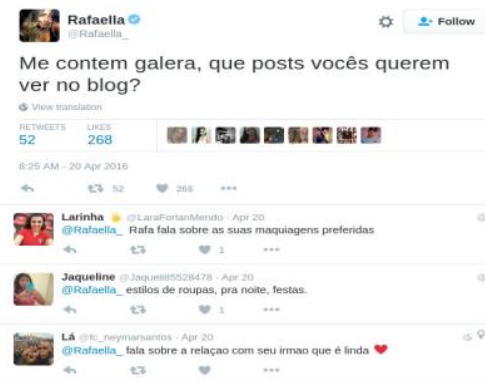

Figura 6. Blogueira perguntando no Twitter quais assuntos os seus leitores gostariam de ver no blog dela.

Os leitores podem colaborar com a criação ou correção de conteúdos no blog através dos comentários nas fotos ou vídeos do Instagram, onde podem solicitar alguma postagem ou assunto a ser discutido na postagem para os administradores do blog, como pode ser observado no comentário da leitora @ derivadosdamoda da Figura 7.

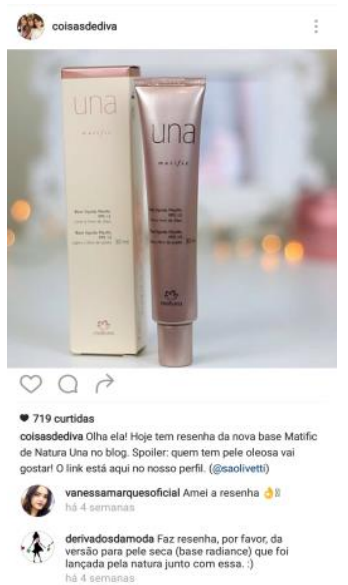

Figura 7. Blogueira divulgando no Instagram um post novo lançado no blog 


\subsection{Interação}

A interação no Snapchat para auxiliar os blogs se dá de forma semelhante que a colaboração, embora seja uma troca de mensagens recíproca no chat ou por vídeo, entre os administradores do blog ou entre leitor e administrador.

No Youtube a interação se dá através dos comentários e das respostas aos comentários deixadas pelos usuários, ou ainda através de um vídeo resposta. Se o dono do canal ou algum usuário deixar um comentário com um link para um post de um blog, onde o assunto do vídeo ou um tema relacionado foi trabalhado, ou mencionar no seu vídeo resposta uma postagem de um blog, está feita a interação a favor do blog.

A interação através do Instagram para ajudar os blogs se dá pelo uso de hashtags (\#), comentários ou mensagens diretas no chat onde é divulgado o conteúdo completo referente a chamada do Instagram através da foto, como pode ser observado na descrição da fato da Figura 6.

A interação no Twitter com o intuito de ajudar os blogs se dá ao utilizar a funcionalidade reply para com idéias para postagens, podendo ou não ter imagens ou vídeos anexados a essas respostas, conforme é possível observar na Figura 8.

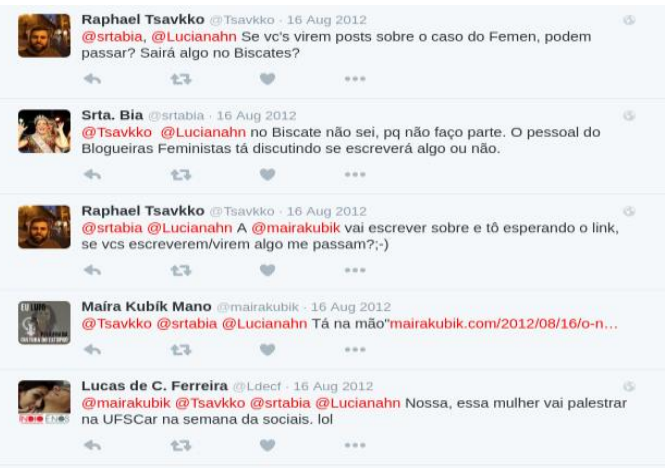

Figura 8. Blogueira interagindo a uma conversa no Twitter e divulgando um link para um post relacionado ao assunto

\subsection{Compartilhamento}

Pelo Snapchat, os administradores do blog podem promover o compartilhamento de imagens, links, mensagens ou vídeos presentes em um post ao enviar snaps no formato de 
vídeo ou foto para seus leitores, como uma amostra do conteúdo da postagem, funcionando como uma âncora para o blog.

O compartilhamento, no Youtube se dá de forma bem semelhante a da interação: através dos comentários e das respostas aos comentários deixadas pelos usuários, ou ainda através de um vídeo resposta. Se o dono do canal ou algum usuário deixar um comentário com um link para um post de um blog, onde o assunto do vídeo ou um tema relacionado foi trabalhado, ou mencionar no seu vídeo resposta uma postagem de um blog, está feita a interação a favor do blog.

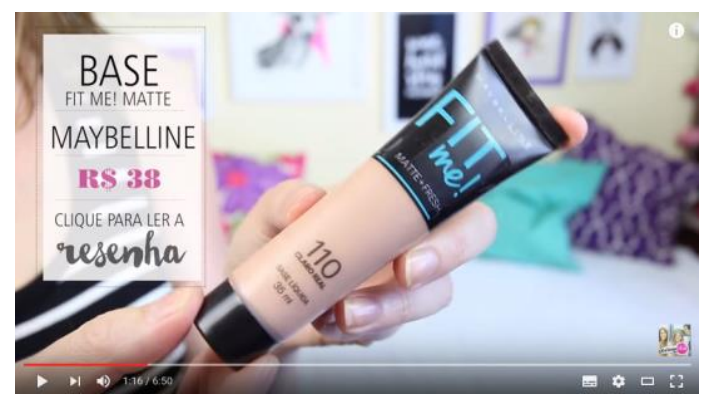

Figura 9. Exemplo de utilização da ferramenta card do Youtube (canto superior direito) e do link direto no vídeo (lado esquerdo)

No Instagram existe uma funcionalidade de compartilhamento em outras mídias sociais digitais, e o dono da foto promove o compartilhamento dessa imagem postada no Instagram que tem um link ou uma âncora para o post relacionado.

No Twitter, assim como no Instagram existe uma funcionalidade de compartilhamento em outras mídias sociais digitais, e o criador do tweet promove o compartilhamento dessa mensagem, imagem ou vídeo postado no Twitter que tem um link ou uma âncora para o post relacionado.

\subsection{Sociabilidade}

A sociabilidade, no Snapchat, pode ser garantida pela interação entre mais de dois usuários, alcançada pelo compartilhamento sucessivo entre mais de dois usuários de uma mesma imagem, informação ou link referente ao conteúdo existente de um post no blog ou em outra mídia social digital que posteriormente fará a âncora para o blog, como na Figura 10.

A sociabilidade se apresenta no Youtube através de uma conversa ou troca de mensagens entre mais de duas pessoas, interagindo, colaborando e/ou compartilhando, 
informações e experiências apreendidas de postagens já existentes ou que auxiliem, de quaisquer maneiras, na criação de um novo post em um blog.

No Instagram, a sociabilidade se apresenta através de uma conversa ou troca de mensagens entre mais de duas pessoas, marcadas pelo uso de marcações e hashtags, onde os usuários interagem, colaboram e/ou compartilham, informações e experiências apreendidas de postagens já existentes ou que auxiliem, de quaisquer maneiras, na criação de um novo post em um blog.

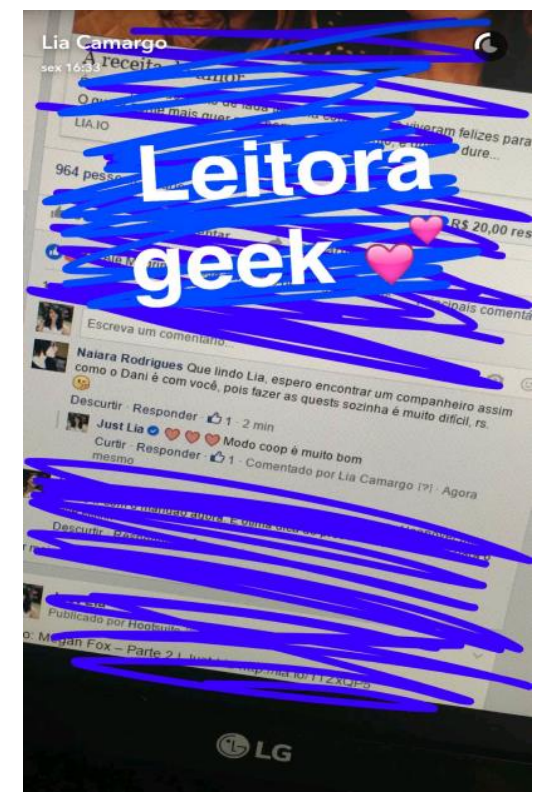

Figura 10. Blogueira divulgando no Snapchat a interação e a sociabilidade entre suas leitoras ao comentar sobre um post compartilhado em outra mídia social digital.

No Twitter, a sociabilidade se apresenta através de uma conversa ou troca de mensagens entre mais de duas pessoas, marcadas pelo uso de menções, respostas (replies) e hashtags, onde os usuários interagem, colaboram e/ou compartilham, informações e experiências, em mensagens de no máximo 140 caracteres, apreendidas de postagens já existentes ou que auxiliem, de quaisquer maneiras, na criação de um novo post em um blog.

\section{CONSIDERAÇÕES FINAIS}

Levando em consideração que as mídias sociais digitais prezam, inicialmente, pela manutenção da praticidade na atividade da sociabilidade entre os usuários, pode-se concluir que este trabalho contribuiu com êxito em indicar estratégias para que blogs possam se manter 
relevantes frente ao surgimento de mídias sociais digitais no cenário da nova ordem de comunicação digital, e além disso, utilizando as mesmas como apoio.

A sociabilidade, em quaisquer uma das mídias sociais escolhidas, não deve ser vista, e principalmente confundida, somente como uma interação entre dois indivíduos, como reforçado na seção 4 deste trabalho, mais como uma forma de permitir a colaboração, interação e compartilhamento contínuos, simultâneas ou não, síncronos ou assíncronos entre os usuários das mídias sociais digitais. Com uma efetiva performance da sociabilidade podese; não garantir que as mídias sociais sejam utilizadas exatamente de acordo com suas vocações, sem que sejam apenas divulgadoras de um mesmo formato de conteúdo em diferentes plataformas; mas assegurar que seja um pontapé inicial nessa direção, podendo ser norteador para trabalhos futuros.

Os objetivos propostos neste trabalho foram atingidos e é correto dizer que ainda existe espaço para os blogs neste novo cenário, assim como existe para novas mídias sociais digitais, contando que sejam respeitadas suas características e objetivos, desde que estas sejam utilizadas como braços midiáticos para auxiliar na sobrevivência dos blogs. Este trabalho auxiliou, ainda, na visualização de como, no escopo do circuito comunicativo, a informação originada nos blogs, pode percorrer as mídias sociais digitais e voltar para os blogs, em uma remissiva externa, agregada com novo conteúdo e experiências.

\section{REFERÊNCIAS}

PIERRE LEVY. Cibercultura. Editora 34. São Paulo, 2010.

CASTELLS, Manuel. A Galáxia Internet: reflexões sobre a Internet, negócios e a sociedade. Zahar. Rio de Janeiro, 2003.

PRIMO, Alex Fernando Teixeira; RECUERO, Raquel da Cunha. Hipertexto cooperativo: uma análise da escrita coletiva a partir dos blogs e da Wikipédia. Revista FAMECOS: mídia, cultura e tecnologia, v. 1, n. 22. Porto Alegre, 2005.

RECUERO, Raquel. Weblogs, webrings e comunidades virtuais. Revista Eletrônica do Grupo Ciberpesquisa. Edição, v. 31. Porto Alegre 2003.

AMARAL, Adriana; RECUERO, Raquel; MONTARDO, Sandra. Blogs. com: estudos sobre blogs e comunicação. São Paulo: Momento Editorial, p. 293, 2009.

AMARAL, Adriana; RECUERO, Raquel; MONTARDO, Sandra. Blogs: mapeando um objeto. Blogs. com: estudos sobre blogs e comunicação. São Paulo: Momento Editorial, p. 27-53, 2009. 
CORRÊA, Elizabeth Saad. A Comunicação Digital nas organizações: tendências e transformações. Revista Organicom, v. 6, n. 10/11. São Paulo, 2011.

LEMOS, André. Cibercidade: as cidades na cibercultura. Editora E-papers. Rio de Janeiro, 2004.

LEMOS, André; LÉVY, Pierre. O futuro da internet: em direção a uma ciberdemocracia planetária. São Paulo: Paulus, 2010.

LEMOS, André. Cibercultura e mobilidade: a era da conexão. Razón y palabra, v. 41. Atizapán de Zaragoza, 2004.

LEMOS, André. Janelas do ciberspaço: comunicação e cibercultura. Editora Sulina. Porto Alegre, 2000.

PRIMO, Alex. O aspecto relacional das interações na Web 2.0. E-Compós (Brasília), v. 9, p. $1-21,2007$.

PRIMO, Alex; SMANIOTTO, Ana. Comunidades de blogs e espaços conversacionais. Revista Prisma.com, n. 3. Lisboa, 2010.

AMARAL, Adriana; RECUERO, Raquel; MONTARDO, Sandra. Blogs. com: estudos sobre blogs e comunicação. São Paulo: Momento Editorial, p. 293, 2009.

BAUMAN, Zygmunt. O Mal-Estar da Pós-Modernidade. Zahar. Rio de Janeiro, 1998.

BAUMAN, Zygmunt. Vida para consumo: a transformação das pessoas em mercadoria. Zahar. Rio de Janeiro, 2008.

JUNIOR, Walter Teixeira Lima. Mídia social conectada. São Paulo, 2009.

GOMES, Maria João. Blogs: um recurso e uma estratégia pedagógica. 2005.VII Simpósio Internacional de Informática Educativa-SIIE05. Disponível em: $<$ https://repositorium. sdum. uminho. pt/bitstream/1822/4499/1/Blogs-final. pdf >. Acesso em, v. 15, 2014.

O'REILLY, Tim. What is Web 2.0: Design patterns and business models for the next generation of software. Communications \& strategies, n. 1, p. 17, 2007.

MARLOW, Cameron. Audience, structure and authority in the weblog community. In: International Communication Association Conference. New Orleans, 2004.

LÉVY, Pierre. Inteligência coletiva (A). Edições Loyola. São Paulo, 2007.

LEMOS, André. As estruturas antropológicas do cyberespaço. Textos de Cultura e Comunicação, v. 35, p. 12-27. Salvador, 1996.

BAUMAN, Zygmunt. Amor líquido: sobre a fragilidade das relações humanas. Rio de Janeiro: Jorge Zahar, 2004. 
SHAH, Nishant. PlayBlog: Pornography, performance and cyberspace. Cut-up. com Magazine, v. 24, n. 09, p. 2005. New York, 2005.

Michaelis: moderno dicionário da língua portuguesa. Melhoramentos, 1998.

Original recebido em: 14 de julho de 2016

Aceito para publicação em: 22 de agosto de 2017

Lutiana Casaroli

Doutoranda em Linguística pelo Programa de Pós-Graduação em Letras e Linguística, da Faculdade de Letras, da Universidade Federal de Goiás (UFG)

lutiana.rp@gmail.com

Juliane Barcelos de Oliveira Pós-graduanda de Especialização em Gestão e Avaliação da Informação pela Faculdade de Informação e Comunicação, da Universidade Federal de Goiás (UFG) juliane.barcelos@gmail.com

\section{(9) $(\Theta \odot$}

Esta obra está licenciado com uma Licença

Creative Commons Atribuição-NãoComercial-CompartilhaIgual 4.0 Internacional 